\title{
Hybrid 'Sinta' Papaya Exhibits Unique ACC Synthase 1 cDNA Isoforms
}

\author{
Marie-Sol P. Hidalgo ${ }^{\dagger}$, Evelyn Mae Tecson-Mendoza ${ }^{\dagger *}$, Antonio C. Laurena ${ }^{\dagger}$ and Jose Ramon Botella \\ Institute of Plant Breeding, College of Agriculture, University of the Philippines Los Baños, College, Laguna 4031, Philippines \\ Plant Genetic Engineering Laboratory, School of Life Sciences, University of Queensland, Brisbane, Qld 4072, Australia
}

Received 8 June 2004, Accepted 21 December 2004

\begin{abstract}
Five ripening-related ACC synthase cDNA isoforms were cloned from $80 \%$ ripe papaya cv. 'Sinta' by reverse transcription-PCR using gene-specific primers. Clone 2 had the longest transcript and contained all common exons and three alternative exons. Clones 3 and 4 contained common exons and one alternative exon each, while clone 1, the most common transcript, contained only the common exons. Clone 5 could be due to cloning artifacts and might not be a unique cDNA fragment. Thus, there are only four isoforms of ACC synthase mRNA. Southern blot analysis indicates that all five clones came from only one gene existing as a single copy in the 'Sinta' papaya genome. Multiple sequence alignment indicates that the four isoforms arise from a single gene, possibly through alternative splicing mechanisms. All the putative alternative exons were present at the 5'-end of the gene comprising the $\mathrm{N}$-terminal region of the protein. 'Sinta' ACC synthase cDNAs were of the capacs 1 type and are most closely related to a $1.4 \mathrm{~kb}$ capacs 1 -type DNA (AJ277160) from Eksotika papaya. No capacs 2-type cDNAs were cloned from 'Sinta' by RT-PCR. This is the first report of possible alternative splicing mechanism in ripening-related ACC synthase genes in hybrid papaya, possibly to modulate or fine-tune gene expression relevant to fruit ripening.
\end{abstract}

Keywords: ACC synthase, Capacs 1, Carica papaya, Papaya

\section{Introduction}

1-Amino-cyclopropane-1-carboxylate synthase (ACC synthase, EC 4.4.1.14) catalyses the committed step in ethylene biosynthesis in higher plants (Yang and Hoffmann, 1984). As a regulatory enzyme, ACC synthase has a short half-life and

\footnotetext{
*To whom correspondence should be addressed.

Tel: 63-49-536-2512; Fax: 63-49-536-2512

E-mail: emtm@laguna.net
}

exists in vivo as a dimer (Li and Mattoo, 1994). At present, the most extensive studies regarding the molecular mechanisms of ACC synthase-regulated fruit ripening are on tomato. The marked increase of ACC and ethylene production is attributed to the expression of two ACC synthase genes, LE ACS2 and LE ACS4 (Olson et al., 1991; Rottman et al., 1991; and Lincoln et al., 1993). In transgenic tomatoes with an antisense ACC synthase gene, the hampered production of ACC synthase leads to very low levels of ethylene generation, and the tomato fruit will not ripen without constant exposure to external sources of ethylene for at least 6 days (Oeller et al., 1991). Consequently, the transgenic tomato exhibited superior post-harvest characteristics, especially in the transport and storage of the fruit.

Such post-harvest characteristics are ideal for papaya, a climacteric fruit with a short shelf life. The quality of the fruit available for local consumption is decreased by rough handling of the fruits at all stages of transport from harvest to the retail market. Papayas with a controlled ripening phase could be developed for the local and export markets resulting in decreased transport and storage costs and are less prone to losses due to spoilage and disease.

To this end, ripening-related Carica papaya ACC synthase (capacs) cDNAs from different cultivars have been cloned. The Australian cultivar 2001 (Mason and Botella, 1997) and Philippine Solo (Laurena et al., 2002) express at least two types of capacs cDNAs: capacs 1 which is highly expressed at the onset of ripening and gradually decreases during ripening and capacs 2 which is not detected at the mature green stage but dramatically increases at the onset of ripening and remains at a high level during the various stages of ripening. The cDNA library from $30 \%$ ripe fruit of the cultivar Solo Sunrise from Hawaii contains capacs 1-type cDNA (Neupane et al., 1998). In addition to published cDNA sequences, four papaya ACC synthase cDNA sequences are accessible through the GenBank sequence database. When compared by phylogenetic analysis, three were identified as capacs 1-type and one as capacs 2-type (Fig. 1). These sequences indicate that in papaya, the ACC synthase gene and its expression in response to ripening is cultivar-dependent. 


\section{Capacs 1}

Capacs 2

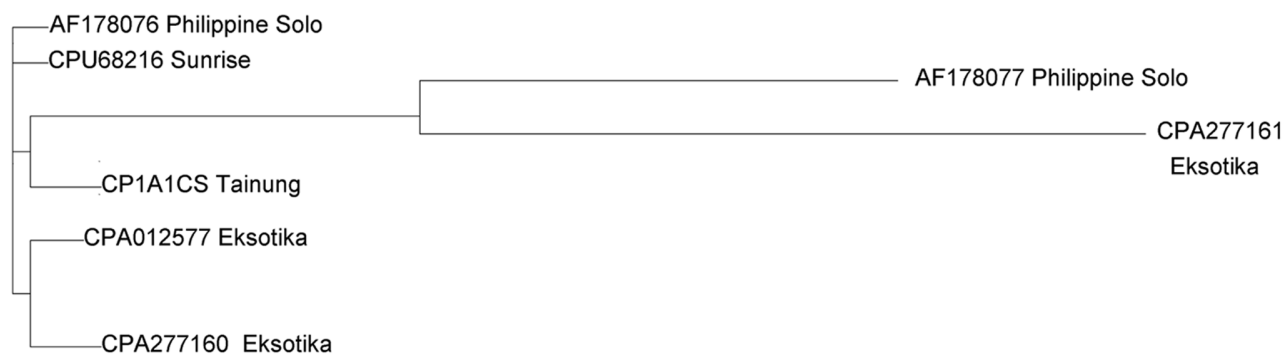

Fig. 1. Phylogenetic relationships of ripening-related papaya ACC synthase nucleotide sequences generated by the Align X Program of the Vector NTI suite. Two clusters of ACC synthase genes were dubbed capacs 1 and 2 by Mason and Botella (1997), which stands for Carica papaya ACC synthase.

Table 1. 'Ole' primers used in cloning ACC synthase by RT-PCR (Mason and Botella, 1997)

\begin{tabular}{clc}
\hline Primer & \multicolumn{1}{c}{ DNA sequence } & Degeneracy \\
\hline Ole 2 $(\mathrm{F})$ & gcT cTA gAT AYT Tyg Ayg gNT ggA Arg c & 64 \\
Ole 4 (R) & Gcg AAT TcR Tcc ATR TTN gcR AAR cA & 64 \\
Ole 5 (F) & ccT gAT cAR Atg ggN YTN gcN gAR AA & 512 \\
Ole 6 (R) & cTc Tgc Agc RAA RcA Nac NcK RAA ccA & 266 \\
\hline
\end{tabular}

Recent reports show that alternative splicing mechanism may explain the presence of protein isoforms, or in general, protein diversity in plants, especially for proteins with regulatory functions (Kazan, 2003). Further, the estimated 5\% of alternatively spliced genes in Arabidopsis, obtained by computational analyses may be an underestimation. Alternative splicing might therefore also explain the presence of isoforms of ACC synthase genes in various plants.

To assist efforts in improving the post-harvest characteristics of a locally-developed hybrid papaya 'Sinta' using antisense technology, we studied the ACC synthase cDNA expressed in $80 \%$ ripe pericarp of the 'Sinta' fruit. We hereby report the cloning and characterization of four capacs 1-type ACC synthase cDNAs which are encoded by a single-copy gene. This indicates that the four cDNAs may have been brought about by three independent alternative splicing events.

\section{Materials and Methods}

Cloning the ACC Synthase by RT-PCR Total RNA from 100 mg $80 \%$ ripe 'Sinta' papaya fruit was prepared using the RNEasy Plant Mini-Kit (Quiagen, Castsworth, USA). Total RNA was visualized and estimated in a $1 \%$ nondenaturing agarose gel. Firststrand cDNA was prepared using the Pharmacia First Strand cDNA Synthesis kit using a gene-specific primer (OLE-4) and $5 \mu \mathrm{g}$ total RNA.

Ripening-related ACC synthase cDNAs were fished out by polymerase-chain reaction (PCR) using two sets of gene-specific primers: OLE $2 \& 4$ and OLE $5 \& 6$ (Table 1 and Fig. 2A) using the following $25 \mu \mathrm{l}$ reaction mix: $3 \mu \mathrm{l} \mathrm{cDNA}$ solution, $0.15 \mathrm{mM}$ each dNTP, $0.75 \mathrm{mM}$ each primer, $1.5 \mathrm{mM} \mathrm{MgCl}_{2}$, and 0.75 unit Taq Polymerase in TE buffer $\mathrm{pH}$ 8.9.
The amplicons were cloned using the pGEM-T Easy cloning kit (Promega, Madison, USA) and transfected to E. coli strain DH 5- $\alpha$. Plasmid minipreps were prepared from transformed bacterial clones. Preliminary characterization of inserts was done by diagnostic digestion of plasmid minipreps with Eco RI.

Sequencing Insert DNAs (amplicons) within the cloning vectors were sequenced using Applied Biosystems PRISM $^{\mathrm{TM}}$ Ready Reaction DyeDeoxy ${ }^{\mathrm{TM}}$ Terminator Cycle Sequencing kit following the manufacturer's instructions. Sequenced samples were run in an Applied Biosystems automatic sequencer (model 373A).

Southern Blotting and labeling Genomic DNA was extracted from $4 \mathrm{~g}$ of papaya leaf using a modified CTAB protocol (Doyle and Doyle, 1990). Ten $\mu$ g DNA were digested each with Bam HI, Eco RI, Hind III, Kpn I, Pst I, and Pvu I, run on a $0.8 \%$ agarose gel, and blotted onto nylon membrane. The blot was probed with the labeled DNA and detected by chemiluminiscent reaction using the DIG High-Prime Labeling and Detection kit (Boeringer Mannheim, Indianapolis, USA). Probes were produced from unique clones amplified by PCR, cleaned, and labeled with digoxigenin-dUTP.

Sequence analysis Relative homologies between nucleotide and polypeptide sequences were done using pairwise BLAST. Nucleotide sequences were edited and combined using the Vector NTI software (Informax, Inc., 1998), while phylogenetic analysis and multiple sequence alignments were obtained using the Clustal W algorithm of the Align X software (Informax, Inc., 1998).

\section{Results and Discussion}

Cloning of ACC synthase cDNAs by RT-PCR High quality total RNA (Fig. 2B) and OLE 4 primer were used for 
A

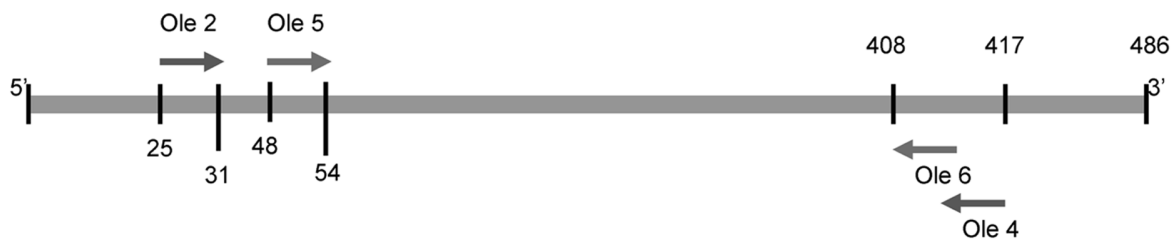

MVLMLRNQEL LSKIATSNGH GEDSPYFDGW KAYDSDPFHP TQNPEGVIQM GLAENQLCFN LIHEWLLKNP EASICTAQGA AEFRDIAIFQ DYHGLAEFRE AVAKFMGKVR RNRASFDPDR IVMSGGATGA HEMIAFCLAD PGDAFLVPTP YYPGFDRDLR WRTGVKLIPV VCESSNDYQI TIEALEAAYE TAQEADIKVK GLLIPNPSNP LGTIITKDTL EALVTETNHK NIHLVCDEIY AATVFSQPEF TSIAEIIEED KICCNRDLIH IIYSLSKDMG FPGFRVGIVY SYNDAVVSCA RKMSSFGLVS SQTQYLIASM LADDEFVDQF IVESRKRLAM RHSFFTQRLA QVGINCLKSN AGLFVWMDLR RLLKEQTFEA EMVLWRVIIN EIKLNVSPGS SFHCSEPGWE RVCFAMMDDK TMEIALSRIK TFMLQHKEAM VPKKKLCWQT SLRLSFSSRY EDIMETPGSF MSPHSPIPQS PLVRART (complete cds, CPU68216, Neupane et al, 1998).

B

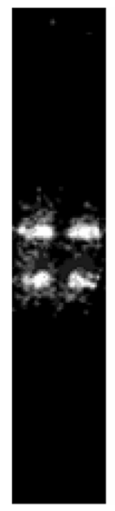

C

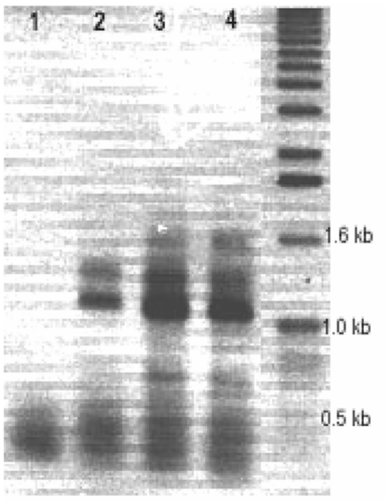

D

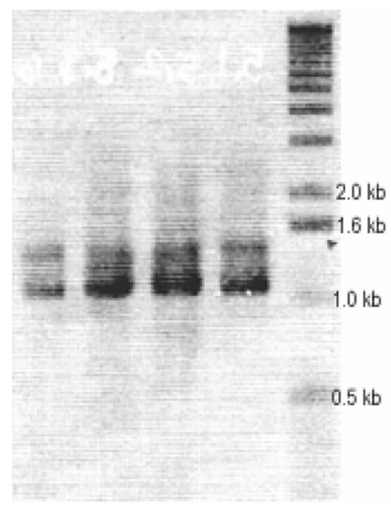

Fig. 2. Fishing out the ACC synthase cDNAs by RT-PCR using OLE primers. (A) Schematic diagram of the position of OLE primers in the ACC synthase gene. Indicated are positions in the resulting polypeptide based on the sequence of Neupane et al., 1998. OLE $2 \& 4$ are in bold, while OLE 5\&6 are boxed. (B) Total RNA extracted from $80 \%$ ripe papaya fruit. (C) PCR of OLE 4-primed cDNA using OLE $2 \& 4$ primer pair using different $\mathrm{MgCl}_{2}$ concentrations. The annealing temperature used was $52^{\circ} \mathrm{C}$. Lane 1: negative control, lane 2: reaction with $1.0 \mathrm{mM}$, lane 3: $1.5 \mathrm{mM}$, lane 4: $2.0 \mathrm{mM}$. Reaction containing $1.5 \mathrm{mM}$ was chosen due to the higher MW bands that were generated in the reaction. (D) Four reamplification reactions using OLE $5 \& 6$ primers. Two strong bands of approximate MW 1.1 and $1.4 \mathrm{~kb}$ and no fragments lower than $1.0 \mathrm{~kb}$ were generated. These amplicons were inserted into pGEM-T Easy.

reverse transcription and were amplified using the OLE 2 and 4 primer pair. Optimization of $\mathrm{MgCl}_{2}$ and dNTP concentrations and reaction buffer for PCR gave rise to sharp and abundant amplification products of approximately 500, 700, and $900 \mathrm{bp}$ as major bands and $1.2 \mathrm{~kb}$ and higher as minor bands (Fig. 2C). A reamplification step using nested primers OLE 5 and 6 was done to remove nonspecific amplification products, resulting in clear, thick amplicons of approximately 1.1 and $1.4 \mathrm{~kb}$ (Fig. 2D).

Characterization of cloned $\boldsymbol{A C C}$ Synthase cDNAs Eco RI digestion of plasmids from 19 minipreps revealed five clone types as shown by their digest profiles (Fig. 3). All inserts had internal Eco RI sites. Clone types were arranged according to frequency and size. Approximately $60 \%$ of the clones contained insert type 1 with aggregate MW of $1.1 \mathrm{~kb}$, the expected amplicon size for OLE 5 and 6 primer pair. Clone types 2, 3, 4 had higher aggregate molecular weights, 1.4, 1.2, and $1.2 \mathrm{~kb}$, respectively, while clone type 5 , with two visible bands, had a total MW lower than the expected amplicon. There were three clones each for types 2 and 3 and one clone each for type 4 and 5.

DNA sequencing The sequences of the five cDNAs (Fig. 4) confirm their identity as ACC synthase genes as they code for polypeptides which contain most of the 12 conserved residues between ACC synthases and aminotransferases (Huang et al., 1991), including four invariant residues present in all ACC synthases (Zarembinski and Theologis, 1994). All five contain the active site motif SLSKDMGPGFR. Phylogenetic analysis groups the five cDNAs with capacs 1-type genes. No capacs 2 was isolated from 'Sinta'.

In comparison to ACC synthase genes of other papaya cultivars, the clones from 'Sinta' show 94-99\% homology to 


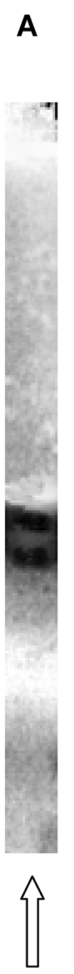

5

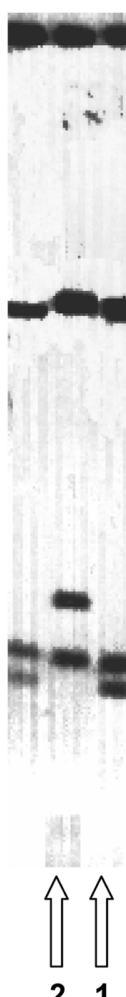

21

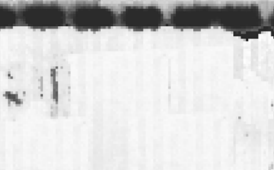

$2+1$

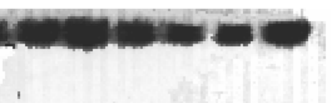

5
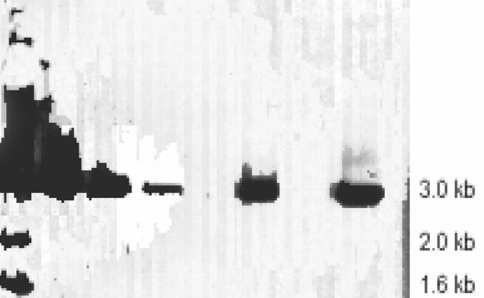

$14.6 \mathrm{~kb}$

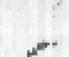

.

.

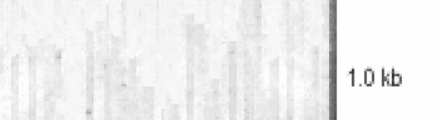

$=2$
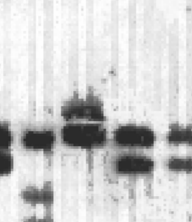

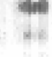

$(1)$

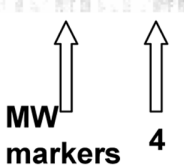

B

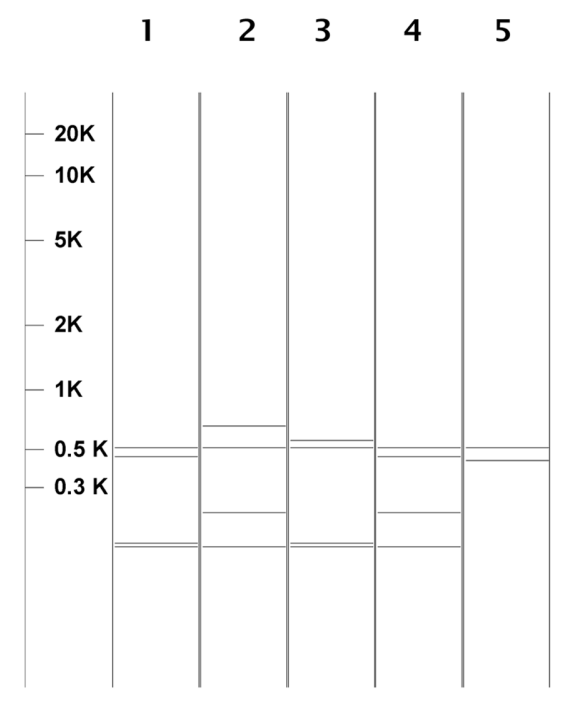

Fig. 3. Diagnostic digest of plasmid minipreps using Eco RI. (A) Enzyme restriction was able to differentiate between five types of inserts, designated clones 1-5. Representative digests for clones 1,2,3, 4, and 5 (separate gel) are indicated by labeled arrows. The pGEM-T Easy plasmid shows up as a constant band of $3 \mathrm{~kb}$ for all the digests. (B) Simulated Eco RI digest of the sequenced clones produced by Vector NTI.

whole capacs 1 -type sequences and 70-82\% homology for short segments of capacs 2. Phylogenetically, 'Sinta' genes are closest to pACCS1A of Eksotika fruit (Fig. 5).

All five cDNAs have restriction sites for the following enzymes: Eco RI, Nsi I, Bst XI, and Sac I (except for clone 5). Theoretical restriction digest profiles for Eco RI agree well with the experimental data. The fifth clone, which occurs as a single clone, appears to be a cloning artifact from clone 2 to which it has $100 \%$ homology as it has no Ole 5 primer sequence at the 5 , end. Clone 5 appears to be due to a recombination event of a pGEM-T Easy vector containing clone 2 . Such events, leading to deletions in the vector inserts have been documented, especially from bacteria transformed with linearized plasmids, which is possible for the pGEM-T Easy vector. In vivo recyclization of in vitro ligation products explains many of the aberrant DNA molecules that are encountered during gene cloning (Conley et al., 1986).

Southern Blot hybridization analysis All four unique cDNA clones were bound to the same bands in the Southern blots (Fig. 6), with some bands exhibiting different signal intensities. The cDNA clones hybridized to 1-3 bands only per restriction lane, a strong indication that the ripeningrelated ACC synthase is a single copy gene. The capacs genes isolated from other papaya cultivars such as Sunrise Solo
(Neupane et al., 1998) and cv. 2001 (Mason and Botella, 1997) are also single copy genes. Additionally, the Southern blot hybridization data gave evidence that the capacs cDNAs were not amplified from contaminating gDNA, as the probes hybridized to both high $(>40 \mathrm{~kb})$ and low $(<2 \mathrm{~kb})$ molecular weight bands for digests of Pst I, Pvu I, and Hind III. As there is no restriction site in the cDNA for these enzymes, the restriction sites are probably found in the intron regions of the gDNA.

Multiple sequence alignment Multiple sequence analysis of all five capacs cDNAs of 'Sinta' revealed regions of high homology interrupted by three segments of 90-111 bp (Fig. 7). These sequences are flanked by evolutionarily conserved splice site sequences, viz, AG:GU(A)AGU at the 5' donor site and CAG:G at the 3' acceptor site (Padgett et al., 1986). As there appears to be only one gene coding for the four unique cDNAs, the sequence alignments indicate that the cDNA clones may be products of three independent alternative splicing events, viz; four constitutive exons (1,3,5, and 7) are present in all four clones, while three alternative exons $(2,4$, and 6) occur in the 5' end and are AT-rich sequences. Clone type 1 , the most dominant of the clones, contains only the constitutive exons. Clones 3 and 4 contain one alternative exon each. Clone 2, the longest, contains all constitutive and 


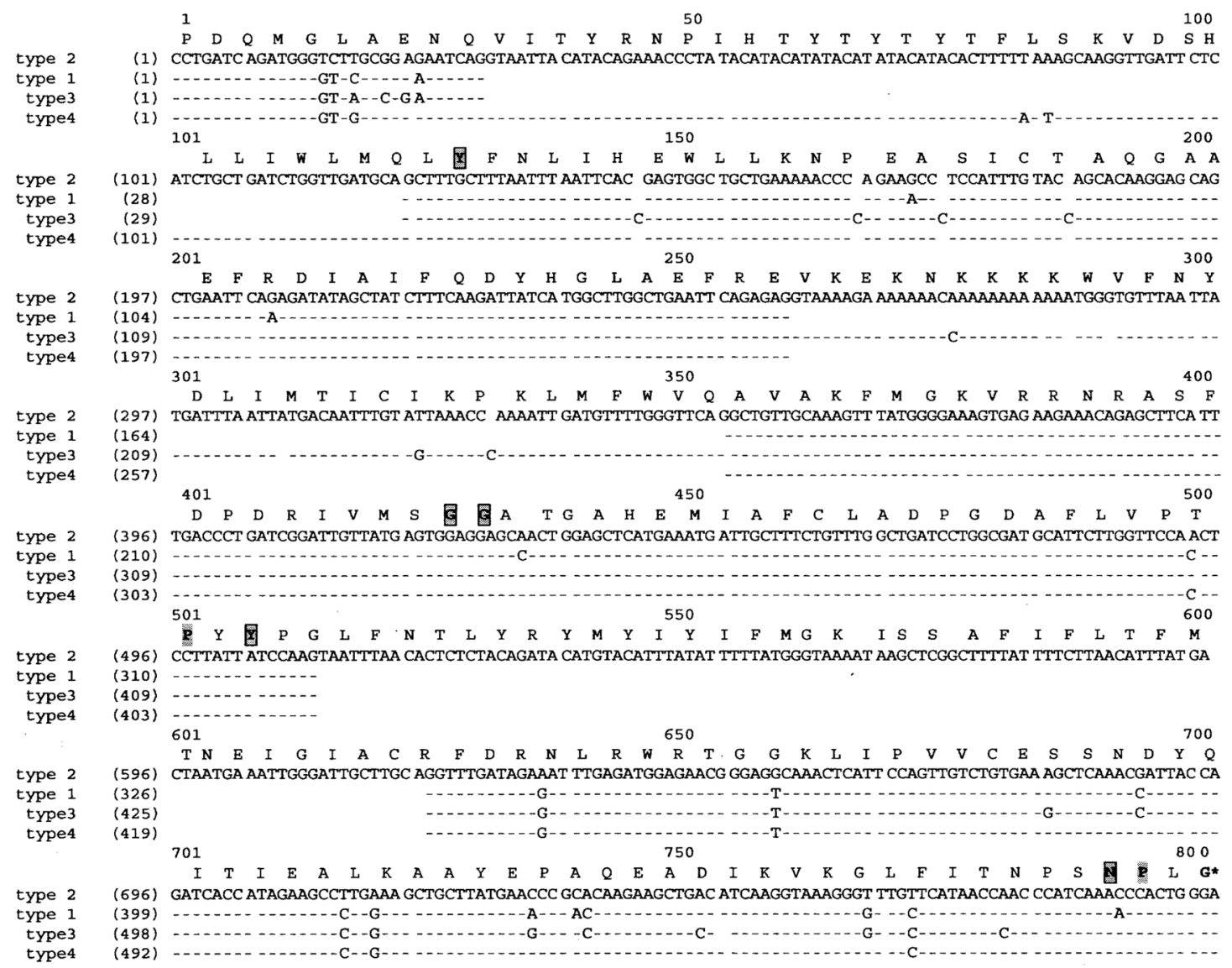

Fig. 4. Nucleotide and deduced amino acid sequences of the four unique ACC synthase cDNAs from papaya cv. 'Sinta'. The active site is underlined and highly conserved residues found in aminotransferases are highlighted with gray. Residues that were found to play important structural and functional roles are boxed. Four residues found to be invariant among ACC synthases have asterisk.

alternative exons.

While there is so far no documented case of alternative splicing in ACC synthase genes, Peck and Kende (1998) have described the presence of two ACC synthase cDNA isoforms $(1.6 \mathrm{~kb}$ and $1.9 \mathrm{~kb})$ in etiolated pea seedlings sprayed with auxin. Based on 5, RACE and oligonucleotide-directed RNAse H mapping, the shorter transcript was the result of an alternative promoter and not alternative splicing. Attempts to express the $1.6 \mathrm{~kb}$ in $E$. coli were not successful indicating that the shorter transcript was not functional or active. This "two transcript conserved response" has been observed in suspension-cultured tomato cells treated with fungal elicitors (Spanu et al., 1993), flooded tomato roots (Olson et al., 1995), wounded tomato fruit ( $\mathrm{Li}$ et al., 1992), organ-specific expression in carnation flowers (ten-Have and Woltering, 1997) and auxin-treated hypocotyls of winter squash (Nakagawa et al., 1991). Kazan (2003) recently noted that alternative splicing might play a significant role in generating protein diversity in plants especially proteins with regulatory functions. Kazan (2003) gave examples of alternatively spliced stress-associated plant genes which include plant disease resistance genes in flax (Ayliff et al., 1999) and an alternative oxidase gene in rice under salt stress (Kong et al.,
2003).

Genomic sequences of ACC synthase from other plants document the presence of introns within the ACC synthase gene, which are similar to the alternative exons of Sinta capacs 1 , are located at the 5' half of the gene. Three introns are present in Arabidopsis ACC2 gene (Liang et al., 1992); two introns in $P S-A C S$ la from pea hypocotyl (Peck and Kende, 1998); three introns in $L E-A C S 3$ of tomato, each 90$230 \mathrm{nt}$ in length (Yip et al., 1992, Kawakita et al., 1994, and Olson et al., 1995); two introns in LE-ACS7, $100 \mathrm{nt}$ in length (Shiu et al., 1998), three introns in $M d-A C S 1$ from apple (Harada et al., 1997), four introns in zucchini $C P-A C C 1 A$ and $1 B$ (Huang et al., 1991), and $L E-A C S 1 A$ and $1 B$. The introns of the $L E-A C S 2$ and 4 genes, 324 and 302 bp in length, respectively, are located at the same positions as the first putative exon in 'Sinta' capacs clones.

The phylogenetic relationships of the ACC synthase sequences for capacs 1 were as expected among cultivars that are known to contain a large proportion of Hawaiian germplasm, namely, Philippine Kapoho and Sunrise. Capacs from hybrids with a parent from a Hawaiian cultivar formed another group. The capacs from Eksotika, a product of the Malaysian cultivar Subang-6 backcrossed several times with 


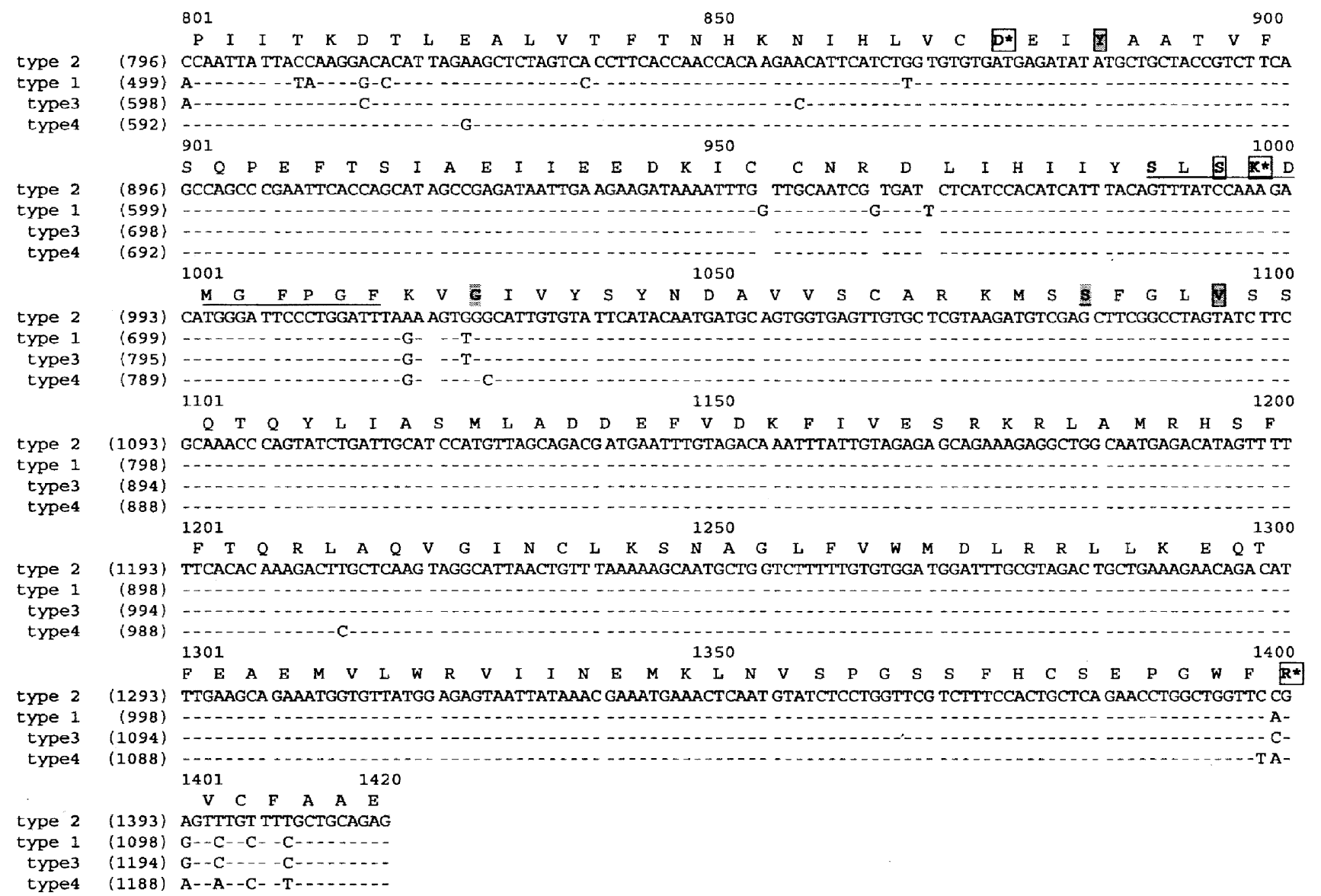

Fig. 4. Continued.

Capacs 1

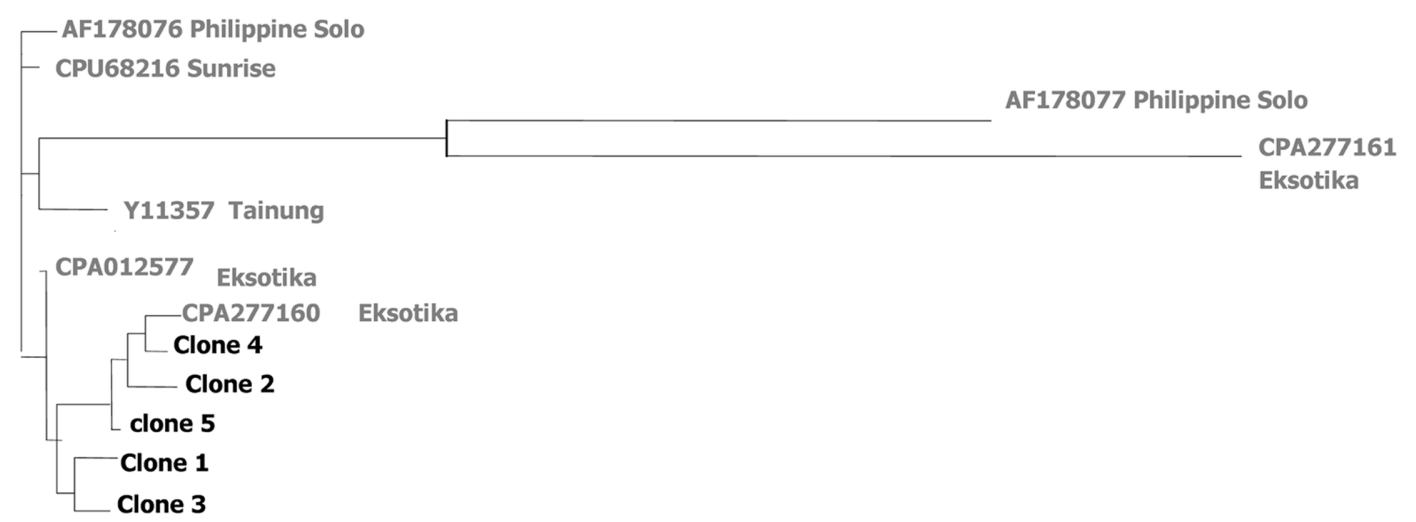

Capacs 2
CPA277161 


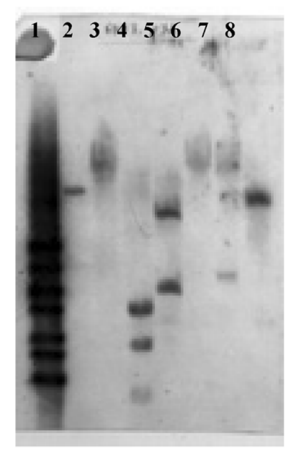

A

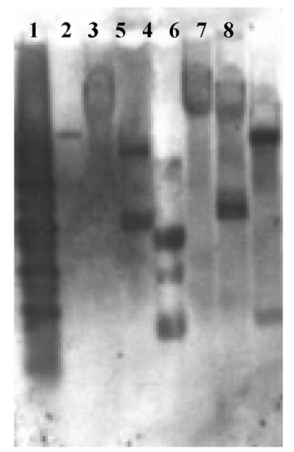

B

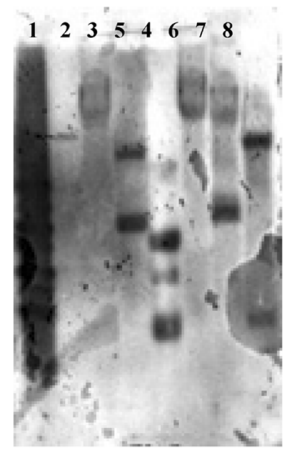

C

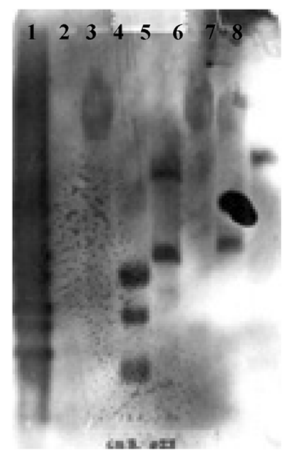

D

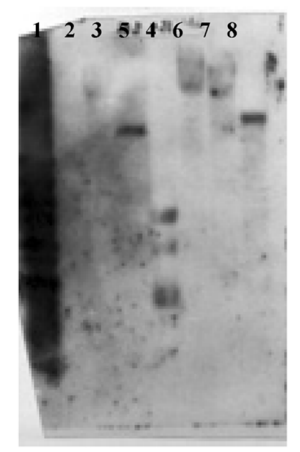

$\mathbf{E}$

Fig. 6. Southern Blot hybridization bands of the 5 cloned ACC synthase cDNAs onto Sinta papaya gDNA digested with restriction enzymes (A) Clone 1 (B) Clone 2, (C) Clone 3, (D) Clone 4, and (E) Clone 5. Lane designations: (1) EL markers, (2) Lambda EcoRI digest, (3) Bam HI, (4) Eco RI, (5) Hind III, (6) Kpn I, (7) Pst I, and (8) Pvu I.

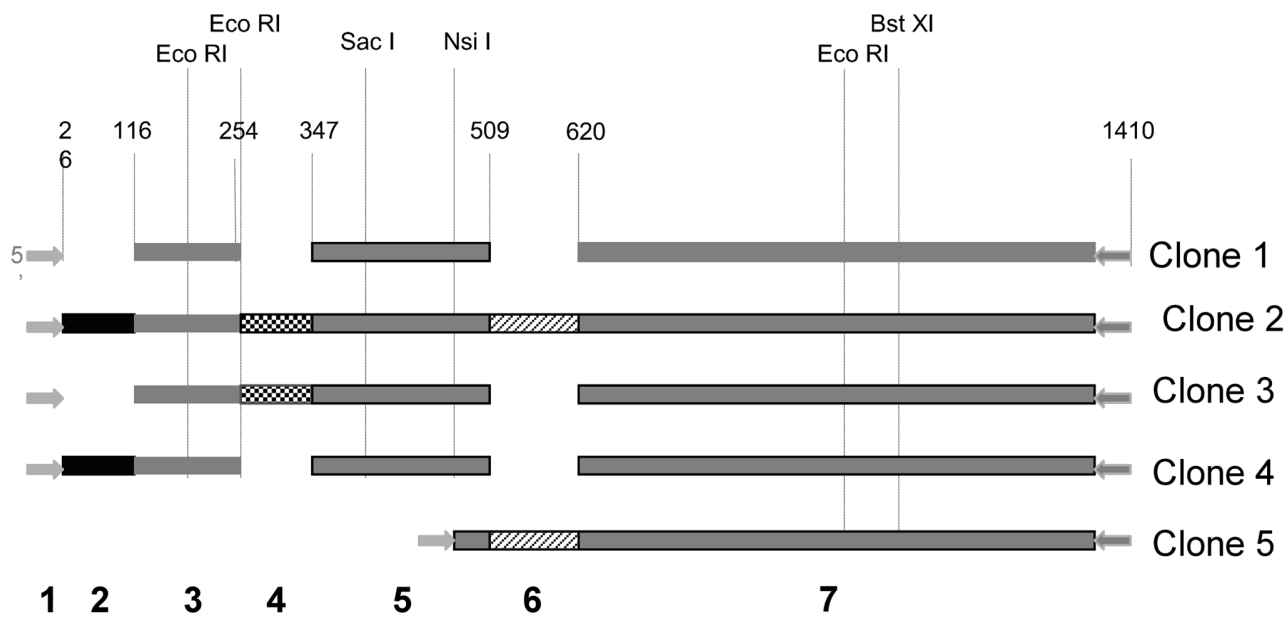

Fig. 7. Diagrammatic representation of the multiple sequence alignment of the five 'Sinta' papaya ACC synthase cDNAs showing probable alternative splicing in the 'Sinta' papaya ACC synthase gene. Included in the diagram are the common restriction sites. Numbering follows the sequence of clone 2. Forward and reverse arrows refer to OLE 5 and 6 primers, respectively. Fragments in gray represent sequences common to the first four clones (constitutive exons), while those in black, with hatched squares and hatched diagonal lines represent alternative exons. Fragments are numbered at the bottom.

Our results further show that the ripening-related ACC synthase type in papaya may differ with the cultivar. While in the hybrid 'Sinta' only the capacs 1 isoforms were detected in the ripe stage, in the Australian cultivar 2001 (Mason and Botella, 1997) and Philippine Solo (Laurena et al., 2002), capacs 2 was the predominant form during ripening and capacs 1 was highly expressed at the mature green stage or onset of ripening. We are now studying the presence of the isoforms of capacs 1 at different stages of ripening in the hybrid papaya 'Sinta' fruit and in different tissues of the papaya plant.

Acknowledgments This study is part of a project funded by the Department of Science and Technology (Philippines)Philippine Council for Agriculture, Forestry and Natural Resources Research and Development (EMTM) and that funded by the Australian Centre for International Agricultural
Research (ACIAR) (JRB and EMTM) and has been implemented at the Institute of Plant Breeding, College of Agriculture, University of the Philippines Los Baños, Laguna, Philippines. This is also part of the MS thesis of the senior author.

\section{References}

Ayliff, M. A., Frost, D. V., Finnegan, E. J., Lawrence, G. J., Anderson, P. A. and Ellis, J. G. (1999) Analysis of the flax L6 rust resistance gene. Plant $J .17,287-292$.

Chan, Y. K. (1987) Backcross method in improvement of papaya (Carica papaya L.). Malays. Appl. Biol. 16, 95-100.

Conley, E. C., Saunders, V. A. and Saunders, J. R. (1988) Deletion and rearrangement of plasmid DNA during transformation of Escherichia coli with linear plasmid molecules. Nucleic Acids Res. 14, 8905-8917. 
Doyle, J. J. and Doyle, J. L. (1990) Isolation of plant DNA from fresh tissue. Focus 12, 13-15.

Harada, T., Sunako, T., Sakuraba, W., Goto, S., Senda, M., Akada, S. and Niizeki, M. (1997) Genomic nucleotide sequence of a ripening-related 1-aminocyclopropane-1-carboxylate synthase gene (Md-ACS1) in apple (accession number U89156). Plant Physiol. 113, 1465.

Huang, P. 1., Parks J. E., Rottmann, W. H. and Theologis, A. (1991) Two genes encoding 1-aminocyclopropane-1-carboxylate synthase in zucchini (Cucurbita pepo) are clustered and similar but differentially regulated. Proc. Natl. Acad. Sci. USA 88, 7021-7025.

Informax Inc. (1998) Vector NTI Suite. Version 5.1, USA.

Kawakita, K., Hennig, L., Lincoln, J. E., Rottmann, W. H., Campbell, A. D., Zarembinski, T., Yu, G. Y., Taylor, L. D. and Theologis, A. (1994) Le-ACS3 sequence, Accession number LEU18055.

Kazan, K. (2003) Alternative splicing and proteome diversity in plants: the tip of the iceberg has just emerged. Trends Plant Sci. 8, 468-471.

Kong, J., Kong, J.-M., Zhang, Z.-G., Zhang, J.-S., Chen, S.-Y. (2003) A new AOX homologous gene OsIM1 from rice (Oryza sativa L.) with an alternative splicing mechanism under salt stress. Theor. Appl. Genet. 107, 326-331.

Laurena, A. C., Magdalita, P. M., Hidalgo, M. S. P., Villegas, V. N., Mendoza, E. M. T. and Botella, J. R. (2002) Cloning and molecular characterization of ripening-related ACC synthase from papaya fruit (Carica papaya L). Acta Hort. 575, 163-170.

Li, N. and Matoo, A. K. (1994) Deletion of the COOH terminal region of ACC synthase, a key protein in the biosynthesis of ethylene, results in catalytically hyperactive, monomeric enzyme. J. Biol. Chem. 269, 6908-6917.

Li, N., Parsons, B. L., Liu, D. and Mattoo, A. K. (1992) Accumulation of wound-inducible ACC synthase transcript in tomato fruit is inhibited by salicylic acid and polyamines. Plant Mol. Biol. 18, 477-487.

Liang, X., Abel, S., Keller, J. A., Shen, N. F. and Theologis, A. (1992) The 1-aminocyclopropane-1-carboxylate synthase gene family of Arabidopsis thaliana. Proc. Acad. Nalt. Sci. USA 89, 11046-11050.

Lincoln, J. E., Campbell, J. E., Oetiker, J., Rottmann, W. H., Oeller, P. W., Shen, N. F. and Theologis, A. (1993) LE-ACS4, a fruit ripening and wound-induced 1-aminocyclopropane-1carboxylate synthase gene of tomato (Lycopersicon esculentum). J. Biol. Chem. 265, 19422-19430.

Mason, M. G. and Botella, J. R. (1997) Identification of two 1aminocyclopropane-1-carboxylate (ACC) synthase cDNAs expressed during papaya (Carica papaya) fruit ripening. Aust. J. Plant Physiol. 24, 239-244.

Nakagawa, N., Mori, H., Yamazaki, K. and Imaseki, H. (1991) Cloning of a complementary DNA for auxin-induced 1aminocyclopropane-1-carboxylate synthase and differential expression of the gene by auxin and wounding. Plant Cell Physiol. 32, 1153-1163.
Neupane, K. R., Mukatira, U. T., Kato, C. and Stiles J. I. (1998) Cloning and characterization of fruit-expressed ACC synthase and ACC oxidase from papaya (Carica papaya L.). Acta Hort. 461, 329-337.

Oeller, P. W., Wong, L. M., Taylor, L. P., Pike, D. A. and Theologis, A. (1991) Reversible inhibition of tomato fruit senescence by antisense RNA. Science 254, 437-439.

Olson, D. C., White, J. A., Edelman, L., Harkins R. N. and Kende, H. (1991) Differential expression of two genes from 1aminocyclopropane-1-carboxylate synthase in tomto fruits. Proc. Natl. Acad. Sci. USA 88, 5340-5344.

Olson, D. C., Oetiker, J. H. and Yang, S. F. (1995) Analysis of LE-ACS 3, an ACC synthase gene expressed during flooding in the roots of tomato plants. J. Biol. Chem. 270, 14056-14061.

Padgett, R. A., Grabowski, P. J., Konaska, M. M., Seiler, S. and Sharp, P. A. (1986) Splicing of messenger RNA precursors. Ann. Rev. Biochem. 55, 1119-1150.

Peck, S. C. and Kende, H. (1998) A gene encoding 1aminocyclopropane-1-carboxylate (ACC) synthase produces two transcripts: elucidation of a conserved response. Plant $J$. 14, 573-581.

Rottman, W. H., Peter, G. F., Oeller, P. W., Keller, J. A., Shen N. F., Nagy, B. P., Taylor, L. P., Cambvell, A. D. and Theologis, A. (1991) 1-Aminocyclopropane-1-carboxylate synthase in tomato is encoded by a multigene family whose transcription is induced during fruit and floral senescence. J. Mol. Biol. 222, 937-961.

Shiu, O. Y., Oetiker, J. H., Yip, W. K. and Yang, S. F. (1998) The promoter of LE-ACS7, an early flooding-induced 1aminocyclopropane-1-carboxylate synthase gene of the tomato, is tagged by a Sol3 transposon. Proc. Natl. Acad. Sci. USA 95, 10334-10339.

Stiles, J. I., Lemme, C., Sondur, S., Morshidi, M. B. and Manshardt, R. (1993) Using randomly amplified polymorphic DNA for evaluating relationships among papaya cultivars. Theor. Appl. Genet. 85, 697-701.

Spanu, P., Boller T. and Kende, H. (1993) Differential accumulation of transcripts of 1-aminocyclopropane-1carboxylate synthase genes in tomato plants infected with Phytophthora infestans and in elicitor-treated tomato cell suspension. J. Plant Physiol. 141, 557-562.

ten-Have A. and Woltering, E. J. (1997) Ethylene biosynthetic genes are differentially expressed during carnation (Dianthus caryophyllus L.) flower senescence. Plant Mol. Biol. 34, 89-97.

Yip, W. K., Dong, J. G., Kenny, J. W., Thompson, G. A. and Yang, S. F. (1990) Characterization and sequencing of the active site of 1-aminocyclopropyl-1-carboxylate synthase. Proc. Natl. Acad. Sci. USA 87, 7930-7934.

Yang, S. F. and Hoffman, N. E. (1984) Ethylene biosynthesis and its regulation in higher plants. Annu. Rev. Plant Physiol. 67, 1207-1214.

Zarembinski, T. I. and Theologis, A. (1994) Ethylene biosynthesis and action: a case of conservation. Plant Mol. Biol. 26, 15791597. 